\title{
Effect of Food Stimulated Liquids and Thermocycling on the Monomer Elution from a Nanofilled Composite
}

\author{
Masumeh Hasani Tabatabaei ${ }^{1}$, Sima Sadrai ${ }^{2}$, Seyed Hossein Bassir ${ }^{3,}$, ${ }^{*}$ Nadia Veisy ${ }^{3}$ and Somaye \\ Dehghan $^{3}$ \\ ${ }^{I}$ Restorative Department and Dental Researches Center, School of Dentistry, Tehran University of Medical Sciences, \\ Tehran, Iran \\ ${ }^{2}$ Pharmaceutics Department, Pharmacy Faculty, Tehran University of Medical Sciences, Tehran, Iran. \\ ${ }^{3}$ Dental Students' Scientific Research Center, School of Dentistry, Tehran University of Medical Science, Tehran, Iran
}

\begin{abstract}
The present study was aimed to evaluate the effects of food simulating liquids and thermocycling on the elution of monomers from a nanofilled resin composite in different immersion times. Five Specimen discs were made from a nano-hybrid composite (Supreme 3M) for each group (Total $=180$ ) and immersed in distilled water (control), citric acid, lactic acid, and 75\% aqueous ethanol solution. The discs were removed after $24 \mathrm{~h}, 48 \mathrm{~h}, 72 \mathrm{~h}, 1 \mathrm{wk}, 4 \mathrm{wk}$, and $12 \mathrm{wk}$. Three groups of samples underwent thermocycling for 1000, 2000 and 3000 cycles. The solutes were analyzed with HPLC for detection of eluted monomers. The results showed that the amount of released TEGDMA was significantly higher than that of Bis-GMA; however, there were not any significant differences between the amount of released BisGMA and UDMA. Moreover, the highest amount of monomers was released from samples immersed in ethanol solution; samples immersed in citric acid and lactic acid significantly released more monomers than those immersed in distilled water. Furthermore, the immersion time in aqueous ethanol solution had an increasing effect on the release of monomers. In addition, the higher amounts of monomers were release from samples immersed in ethanol and citric acid which underwent a higher number of thermal cycles. In conclusion, food and drink stimulated liquids used in this study increased the amount of some of the monomers released from composite resin. Thermal shocks and storage time are other factors that increased the release of monomers from the composite resin.
\end{abstract}

Keywords: Bisphenol A-Glycidyl Methacrylate, Composite Resins, Elution, Monomer, Polymerization, Thermocycling.

\section{INTRODUCTION}

Resin based dental materials such as composite resins are widely used in modern dentistry. Mechanical and physical properties of resin composite restorations are highly related with their polymerization [1]. Several studies have shown that a complete conversion of monomers is not possible and, in the best conditions, only $70-75 \%$ of monomers can convert to polymer during the process of polymerization [2-4]. Rode and Kawano found that the degree of conversion of a dental composite (Z250) cured with high intensity halogen, LED, or argon laser curing unites varies between $35-70 \%$ [5]. It has shown than unreacted monomers remain in the mass of restoration and release into the surrounding area (dentine, pulp, or oral cavity) which can negatively affect the biocompatibility of the material $[6,7]$.

Clinical degradation of resin composites even in the absence of mechanical loading and abrasive forces has been reported $[3,5]$. Composite restorations are exposed to

\footnotetext{
*Address correspondence to this author at the Dental Students' Scientific Research Center, School of Dentistry, Tehran University of Medical Science, North Amir Abad Street, 1439955991, Tehran, Iran;

Tel: +98 21 88492345; Fax: +98 21 88507688;

E-mail:hosseinbassir@hotmail.com
}

chemical agents found in saliva, food, and beverages. Some of these chemical agents may accelerate the degradation of composite resins and increase the elution of unreacted monomers. Previous studies have reported that these agents have softening and hydrolyzing effects on dental composites which attribute to the degradation of the polymer matrix [810]. Moreover, some food and drinks (coffee and tea) can cause thermal shocks in oral environment which would accelerate displacing and leaching of unreacted monomers due to the high values of temperature.

The chemical environment in the oral cavity may have a considerable influence on in vivo degradation of resin composite [11]. Therefore, to evaluate the amount of released monomers from dental composites, the role of chemical components which are present in clinical condition should not be neglected. Lactic acid and citric acid could stimulate the clinical condition of oral environment because they are common chemical components that are present in foods, fruits and beverages. In addition, 75\% aqueous ethanol solution has been the solvent of choice to stimulate and accelerate aging of restorations in several studies because it has the solubility parameter which matches that of most monomers which are present in the chemical structure of resins composite $[3,12,13]$. 
Table 1. Mean Values $(\mu \mathrm{g} / \mathrm{mL})$ and Standard Deviation of Released Monomers in Different Medias (2 mL) and Different Immersion Times

\begin{tabular}{|c|c|c|c|c|c|c|c|c|c|c|c|c|c|}
\hline \multirow{2}{*}{ Time } & \multicolumn{4}{|c|}{ Bis-GMA } & \multicolumn{4}{|c|}{ TEGDMA } & \multicolumn{4}{|c|}{ UDMA } & \multirow{2}{*}{$\begin{array}{c}\text { BIS-EMA } \\
\text { Ethanol }\end{array}$} \\
\hline & Water & Citric & Lactic & Ethanol & Water & Citric & Lactic & Ethanol & Water & Citric & Lactic & Ethanol & \\
\hline 1 & $\begin{array}{c}6.5 \\
(0.6) \\
\end{array}$ & $\begin{array}{c}5.7 \\
(0.6)\end{array}$ & $\begin{array}{c}5.6 \\
(0.2)\end{array}$ & $\begin{array}{c}6 \\
(1.1)\end{array}$ & $\begin{array}{c}12 \\
(1.5)\end{array}$ & $\begin{array}{l}10.5 \\
(3.3)\end{array}$ & $\begin{array}{c}12 \\
(0.7)\end{array}$ & $\begin{array}{l}19.8 \\
(2.9)\end{array}$ & $\begin{array}{c}9.1 \\
(0.2)\end{array}$ & $\begin{array}{c}5.8 \\
(0.8) \\
\end{array}$ & $\begin{array}{c}9 \\
(0.6)\end{array}$ & $\begin{array}{c}3.6 \\
(4.2)\end{array}$ & $\begin{array}{l}41.5 \\
(4.7)\end{array}$ \\
\hline 2 & $\begin{array}{c}5 \\
(0.5)\end{array}$ & $\begin{array}{c}6.8 \\
(0.7)\end{array}$ & $\begin{array}{c}5.6 \\
(0.7)\end{array}$ & $\begin{array}{c}7 \\
(1.5)\end{array}$ & $\begin{array}{l}10.8 \\
(2.9)\end{array}$ & $\begin{array}{l}15.4 \\
(1.2)\end{array}$ & $\begin{array}{l}16.2 \\
(2.3)\end{array}$ & $\begin{array}{l}19.7 \\
(3.5)\end{array}$ & $\begin{array}{c}6.7 \\
(1.1)\end{array}$ & $\begin{array}{l}7.11 \\
(1.6)\end{array}$ & $\begin{array}{l}8.3 \\
(2)\end{array}$ & $\begin{array}{c}0.7 \\
(0.1)\end{array}$ & $\begin{array}{l}35.5 \\
(2.6)\end{array}$ \\
\hline 3 & $\begin{array}{c}6.5 \\
(0.5)\end{array}$ & $\begin{array}{c}7.7 \\
(0.2)\end{array}$ & $\begin{array}{c}9.3 \\
(3.1)\end{array}$ & $\begin{array}{c}8.7 \\
(1.8)\end{array}$ & $\begin{array}{c}9.8 \\
(2.3)\end{array}$ & $\begin{array}{l}14.5 \\
(1.5)\end{array}$ & $\begin{array}{l}16.2 \\
(0.8)\end{array}$ & $\begin{array}{l}20.8 \\
(5.3)\end{array}$ & $\begin{array}{c}6.5 \\
(0.8)\end{array}$ & $\begin{array}{l}10 . \\
(0.9)\end{array}$ & $\begin{array}{l}13.4 \\
(2.9)\end{array}$ & $\begin{array}{c}1.67 \\
(2)\end{array}$ & $\begin{array}{c}36 \\
(12.5)\end{array}$ \\
\hline 4 & $\begin{array}{c}5.6 \\
(1.5)\end{array}$ & $\begin{array}{l}10.5 \\
(0.5)\end{array}$ & $\begin{array}{l}11.4 \\
(0.7)\end{array}$ & $\begin{array}{l}17.3 \\
(0.2)\end{array}$ & $\begin{array}{c}4.3 \\
(1.7)\end{array}$ & $\begin{array}{l}21.1 \\
(4.5)\end{array}$ & $\begin{array}{l}24.2 \\
(1.8)\end{array}$ & $\begin{array}{c}21.2 \\
(11.5)\end{array}$ & $\begin{array}{c}4.8 \\
(0.8)\end{array}$ & $\begin{array}{c}9.8 \\
(0.8)\end{array}$ & $\begin{array}{c}15.8 \\
(2.1)\end{array}$ & $\begin{array}{l}105.8 \\
(51.5)\end{array}$ & $\begin{array}{c}65.5 \\
(32.5)\end{array}$ \\
\hline 5 & $\begin{array}{c}0.7 \\
(0.5)\end{array}$ & $\begin{array}{l}13.8 \\
(1.5)\end{array}$ & $\begin{array}{l}13.2 \\
(1.5)\end{array}$ & $\begin{array}{c}32.3 \\
(0.01)\end{array}$ & $\begin{array}{c}2 \\
(0.6)\end{array}$ & $\begin{array}{c}58 \\
(16.8)\end{array}$ & $\begin{array}{c}39 \\
(8.0)\end{array}$ & $\begin{array}{c}24.8 \\
(0.01)\end{array}$ & $\begin{array}{c}1.9 \\
(0.5)\end{array}$ & $\begin{array}{l}10.8 \\
(1.9)\end{array}$ & $\begin{array}{l}14.5 \\
(3.6)\end{array}$ & N D & $\begin{array}{c}68.6 \\
(12.6)\end{array}$ \\
\hline 6 & $\begin{array}{c}0.6 \\
(0.1)\end{array}$ & $\begin{array}{l}11.5 \\
(2.5)\end{array}$ & $\begin{array}{c}6.5 \\
(1.5)\end{array}$ & $\begin{array}{l}16.5 \\
(2.8)\end{array}$ & $\begin{array}{c}44.6 \\
(15.5)\end{array}$ & $\begin{array}{c}11.2 \\
(12.4)\end{array}$ & $\begin{array}{c}2.2 \\
(0.3)\end{array}$ & $\begin{array}{l}115.67 \\
(26.3)\end{array}$ & $\begin{array}{c}0.6 \\
(0.3)\end{array}$ & $\begin{array}{l}14.2 \\
(0.5)\end{array}$ & $\begin{array}{c}6.6 \\
(1.4)\end{array}$ & N D & $\begin{array}{c}406.5 \\
(332.5)\end{array}$ \\
\hline
\end{tabular}

The abbreviations of groups: 1: $24 \mathrm{~h}, 2: 48 \mathrm{~h}, 3: 72 \mathrm{~h}, 4: 1 \mathrm{wk}, 5: 4 \mathrm{wk}, 6: 12 \mathrm{wk}, \mathrm{N}$ D: Non-Detectable

There are some studies which have evaluated the release of monomers from dental composite in the short time. It has been estimated that the maximum release of intact monomers from resin composites is within the first $24 \mathrm{~h}$ after the polymerization $[3,14,15]$. According to Ferracane and Condon, 50\% of the leachable monomers are eluted within the first 3 hours after polymerization [16]. However, in addition to the release of monomers from dental composites immediately after polymerization, composite components could release into the oral cavity as a consequence of a slow and long term degradation of dental composites. There is still not a long term pattern reported for the leaching of monomers from resin composites.

Therefore, the aim of the present study was to evaluate the effects of thermocycling and also food simulating liquids such as citric acid, lactic acid, 75\% aqueous ethanol solution, and distilled water on the elution of monomers from a nanofilled composite in the $24 \mathrm{~h}, 48 \mathrm{~h}, 72 \mathrm{~h}, 1 \mathrm{wk}, 4 \mathrm{wk}$ and 12 wk period intervals.

\section{MATERIALS AND METHODOLOGY}

A nano-hybrid resin composite (shade A2, Filtek supreme, 3M ESPE, Seefeld, Germany) was employed in the present study. Specimen discs of $5 \mathrm{~mm}$ in diameter and 3 $\mathrm{mm}$ in thickness were made using a stainless steel mold. The mold was sandwiched between two pieces of transparent film and two glass microscope slides. The glass slide was pressed against the composite material, and excess material was extruded before polymerization process. The specimens were cured using a tungsten-halogen light-curing unit (Optilux 501, KerrHawe. SA, Bioggio, Switzerland) with an output intensity of $650 \mathrm{~mW} / \mathrm{cm}^{2}$. Curing was performed from each surface of composite discs for $40 \mathrm{~s}$. The intensity of the light emitted from the curing unit was checked periodically using a commercial radiometer (Bisco, IL, USA).

The present study comprised of 36 study groups. Five discs were made for each group (Total specimens $=180$ ). Immediately after curing, composite specimens of each group were immersed in glass vials containing $2 \mathrm{ml}$ of one of

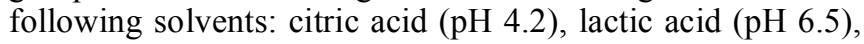
$75 \%$ aqueous ethanol solution, and distilled water (control).
Then, glass vials of 24 groups ( 4 solvent $* 6$ time points) were placed in an incubator at $37^{\circ} \mathrm{C}$ for $24 \mathrm{~h}, 48 \mathrm{~h}, 72 \mathrm{~h}, 1$ $\mathrm{wk}, 4 \mathrm{wk}$, or $12 \mathrm{wk}$. The specimens of the other 12 groups (4 solvent *3 thermocycling) underwent 1000, 2000, 3000 thermal cycles to determine the effect of thermal shocks. After each period, the specimens were removed from containers, and the solvents were then subjected to HPLC analysis to detect the amount of eluted monomers from the composite specimens. The studied monomers with HPLC were:

1. Bis-GMA (Bisphenol A Glycidyl Dimethacrylate ((Aldrich, WI, USA).

2. TEGDMA (Trietyleneglycol dimethacrylate ((Aldrich).

3. Bis-EMA (Bisphenol A Ethoxylate dimethacrylate) (Aldrich).

4. UDMA (Urethan dimethacrylate) (Aldrich).

The HPLC consists: a 600 E Waters (Waters, MA, USA) system controller liquid chromatograph, equipped with a UVVis Detector Waters 486, an ODS3 column ( $5 \mu \mathrm{m}, 4 \mathrm{~mm}$ i.d. $125 \mathrm{~mm}$ length). The mobile phase was acetonitrile/water $(75 / 25 \% \mathrm{v} / \mathrm{v})$ at a flow rate of $1.2 \mathrm{~mL} / \mathrm{min}$ at room temperature. Detection and quantitative analysis of components were performed by comparison of the elution time and the integration of absorption peak area of the test samples with those of the standard samples. In the present experimental condition, the retention time of HPLC peaks of the standard solutions of TEGDMA, Bis-GMA, UDMA, and Bis-EMA were found to be $1.90,2.18,2.27$, and 8 minutes, respectively.

A two-way analysis of variance (ANOVA) test was used to evaluate the effects of the factors (type of solvent and immersion time) on the amount of leachable monomers. Tukey-Kramer test was used for pair-wise comparisons. Statistical significance was set at $\alpha=0.05$.

\section{RESULTS}

The mean values and standard deviation of eluted monomers for the different immersion times and solvents are given in Table 1. Table 2 shows the mean values and standard deviation of eluted monomers after thermocycling. 
Table 2. Mean Values $(\mu \mathrm{g} / \mathrm{mL})$ and Standard Deviation of Released Monomers in Different Medias (2 mL) and Different Cycles of Thermocycling

\begin{tabular}{|c|c|c|c|c|c|c|c|c|c|c|c|c|c|}
\hline \multirow[t]{2}{*}{ Cycles } & \multicolumn{4}{|c|}{ Bis-GMA } & \multicolumn{4}{|c|}{ TEGDMA } & \multicolumn{4}{|c|}{ UDMA } & \multirow{2}{*}{$\begin{array}{c}\text { BIS-EMA } \\
\text { Ethanol }\end{array}$} \\
\hline & Water & Citric & Lactic & Ethanol & Water & Citric & Lactic & Ethanol & Water & Citric & Lactic & Ethanol & \\
\hline 1000 & $\begin{array}{c}5.3 \\
(0.3)\end{array}$ & $\begin{array}{l}5.8 \\
(1)\end{array}$ & $\begin{array}{c}6.3 \\
(0.3)\end{array}$ & $\begin{array}{c}4.7 \\
(0.6)\end{array}$ & $\begin{array}{l}10.7 \\
(1.5)\end{array}$ & $\begin{array}{l}11.0 \\
(2.6)\end{array}$ & $\begin{array}{l}13.1 \\
(1.6)\end{array}$ & $\begin{array}{l}17.7 \\
(4.1)\end{array}$ & $\begin{array}{l}11.2 \\
(1)\end{array}$ & $\begin{array}{c}8 \\
(0.5)\end{array}$ & $\begin{array}{l}13.5 \\
(2.4)\end{array}$ & $\begin{array}{l}2.6 \\
(4)\end{array}$ & $\begin{array}{l}27.5 \\
(6.5)\end{array}$ \\
\hline 2000 & $\begin{array}{c}6.5 \\
(1.5)\end{array}$ & $\begin{array}{c}7.7 \\
(2.3)\end{array}$ & $\begin{array}{c}8 \\
(1.2)\end{array}$ & N D & $\begin{array}{l}13.1 \\
(3.8)\end{array}$ & $\begin{array}{c}15 \\
(4.5)\end{array}$ & $\begin{array}{l}17.5 \\
(4.6)\end{array}$ & N D & $\begin{array}{c}8.6 \\
(3.6)\end{array}$ & $\begin{array}{c}8.1 \\
(3.2)\end{array}$ & $\begin{array}{l}12.7 \\
(1.7)\end{array}$ & N D & N D \\
\hline 3000 & $\begin{array}{l}2.1 \\
(1)\end{array}$ & $\begin{array}{l}12.3 \\
(0.2)\end{array}$ & $\begin{array}{l}10.8 \\
(0.8)\end{array}$ & N D & $\begin{array}{c}3.5 \\
(1.7)\end{array}$ & $\begin{array}{l}37.8 \\
(3.2)\end{array}$ & $\begin{array}{l}14.8 \\
(4)\end{array}$ & $\begin{array}{c}32.1 \\
(13.3)\end{array}$ & $\begin{array}{c}3.9 \\
(2.7)\end{array}$ & $\begin{array}{l}23.3 \\
(1.7)\end{array}$ & $\begin{array}{l}13.8 \\
(1.9)\end{array}$ & $\begin{array}{l}119.5 \\
(62.1)\end{array}$ & $\begin{array}{l}108.2 \\
(33.5)\end{array}$ \\
\hline
\end{tabular}

N D: Non-Detectable

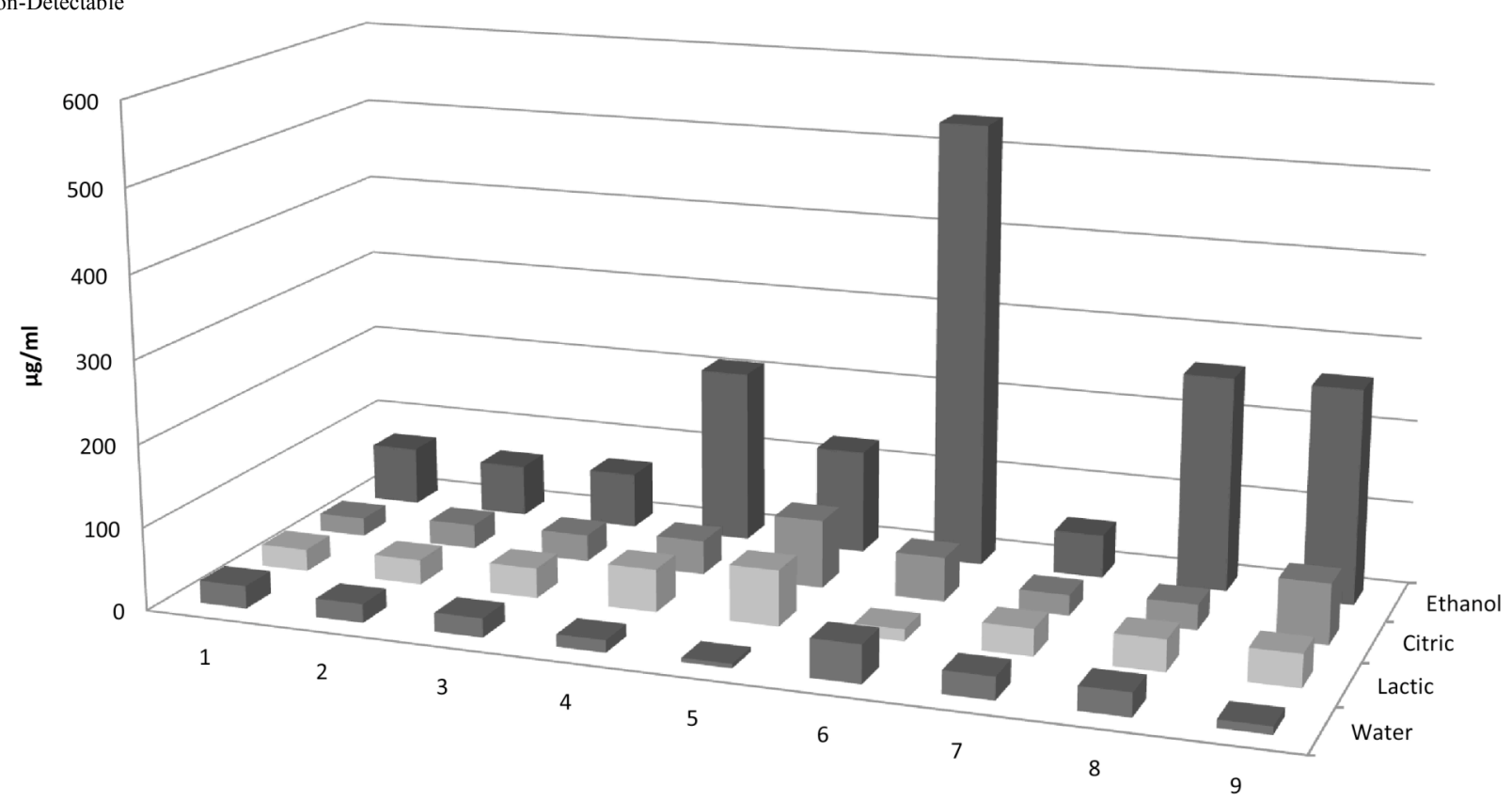

Fig. (1). The relationship between immersion medias and different immersion times and thermocycling and total monomer release, abbreviations of groups are: 1: $24 \mathrm{~h}, 2: 48 \mathrm{~h}, 3: 72 \mathrm{~h}, 4: 1 \mathrm{wk}, 5: 4 \mathrm{wk}, 6: 12 \mathrm{wk}$. 7: 1000 cycles, 8: 2000 cycles, 9:3000 cycles.

The amount of TEGDMA leached from the samples was significantly higher than that of Bis-GMA; however, there were not any significant differences between the amounts of eluted Bis-GMA and UDMA (Fig. 1). Furthermore, the highest amount of monomers was released into $75 \%$ aqueous ethanol solution. The samples immersed in citric acid and lactic acid significantly released more monomer than those immersed in distilled water. It was found that sample immersed in distilled water released the lowest amount of monomers. In addition, the immersion time in aqueous ethanol solution had an increasing effect on the release of monomers, but this effect was not seen in the other groups. Moreover, the higher amounts of monomers were release from the samples which underwent a higher number of thermal cycles.

\subsection{Bis-GMA}

There were no significant differences in the amount of leached Bis-GMA between four media at 24, 48, 72h; however, a higher amount of Bis-GMA was release into the ethanol solution than the other solvents at 1,4 and $12 \mathrm{wk}$.
The effect of immersion time on elution of Bis-GMA into distilled water was significant, and the amount of released Bis-GMA was less at 4 and 12 wk compared to the other time points $(\mathrm{P}<0.001)$. For the samples immersed in acid citric, immersion time had not any significant effect on the elution of Bis-GMA. For the samples immersed in acid lactic and ethanol, the highest amount of eluted Bis-GMA was at 4 wk $(\mathrm{P}<0.001)$.

There were no significant differences in the amount of released Bis-GMA from the samples which underwent different thermal cycles (Fig. 2).

\subsection{UDMA}

UDMA was released less from the samples immersed in ethanol than those immersed in the other solvents at $24 \mathrm{~h}, 48 \mathrm{~h}$ and $72 \mathrm{~h}$, but it was released more from the samples immersed in ethanol than those immersed in the other solvents at $1 \mathrm{wk}$. At $4 \mathrm{wk}$ and $12 \mathrm{wk}$, the samples immersed in water significantly released less UDMA than those immersed in the other solvents. 


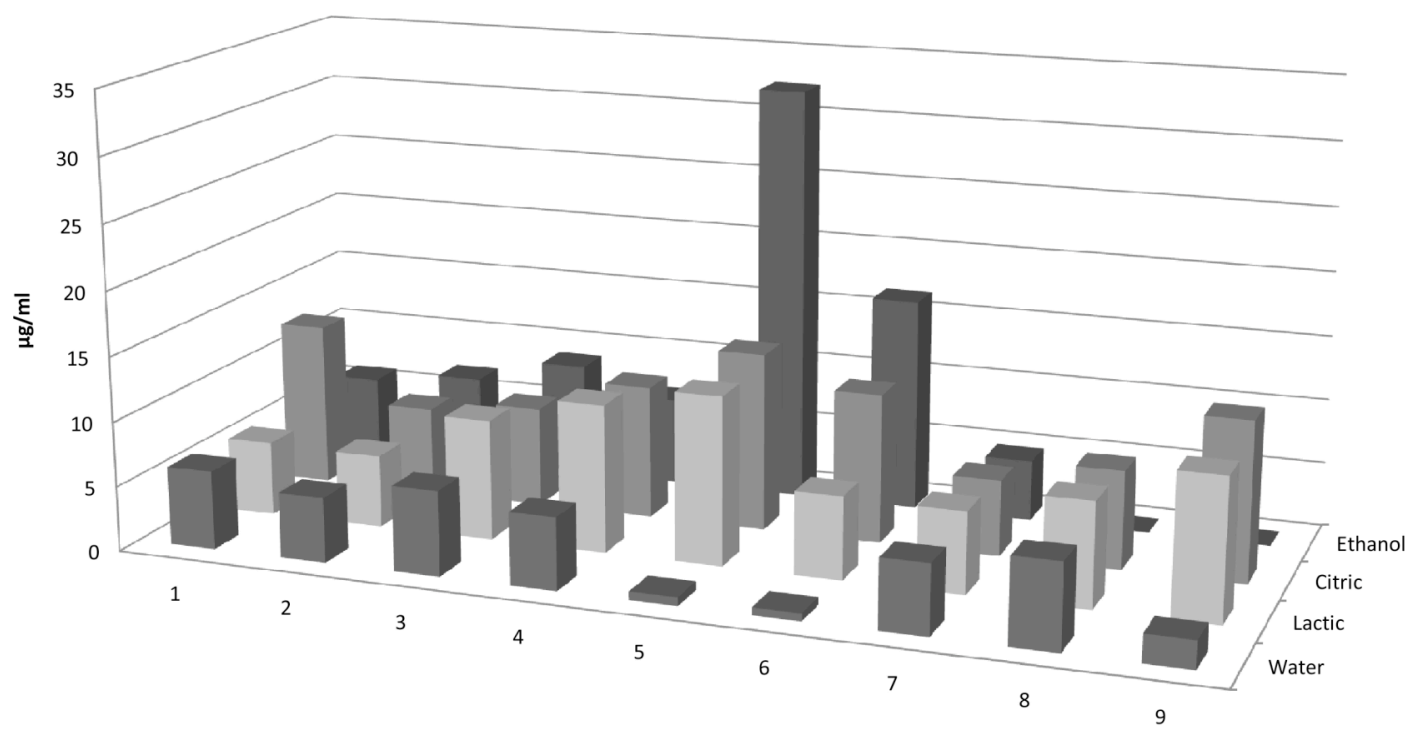

Fig. (2). The relationship between immersion medias and different immersion times and thermocycling and Bis-GMA release; abbreviations of groups are: 1: $24 \mathrm{~h}, 2: 48 \mathrm{~h}, 3: 72 \mathrm{~h}, 4: 1 \mathrm{wk}, 5: 4 \mathrm{wk}, 6: 12 \mathrm{wk}, 7: 1000$ cycles, 8: 2000 cycles, 9: 3000 cycles.

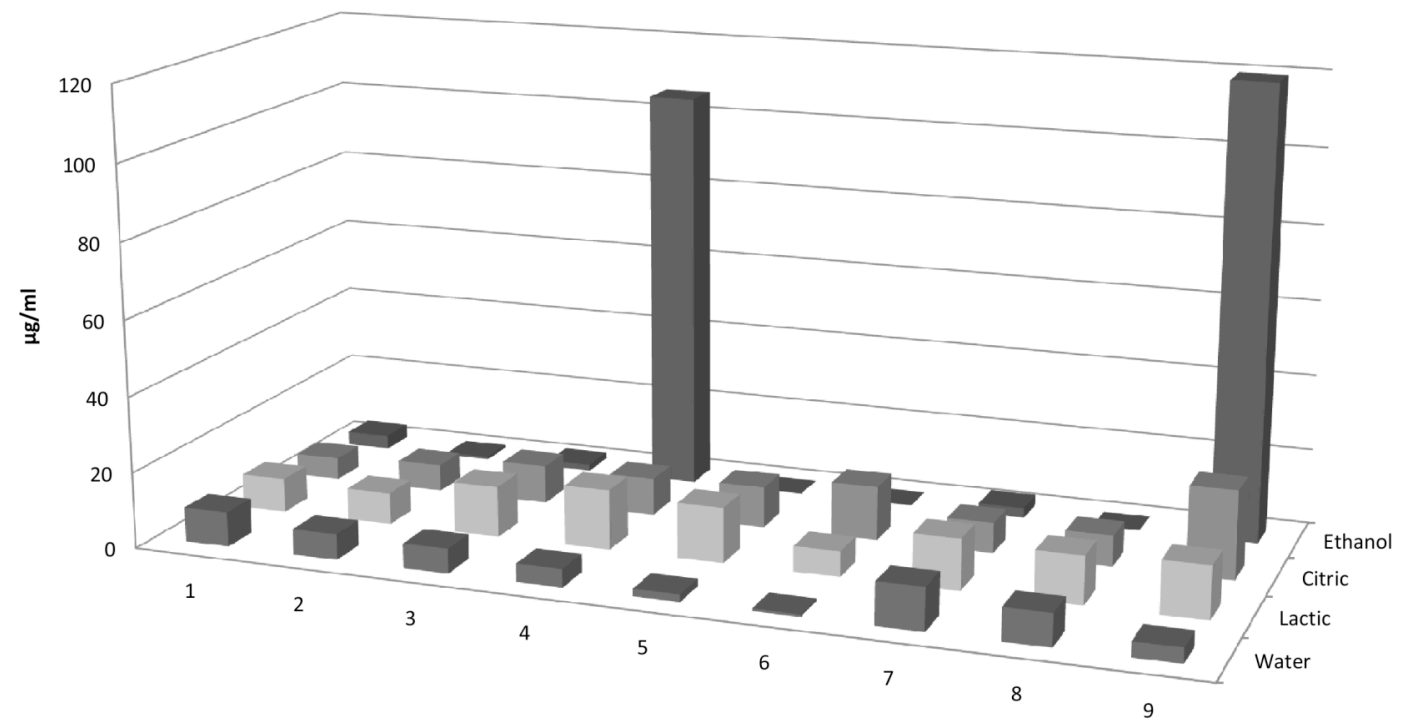

Fig. (3). The relationship between immersion medias and different immersion times and thermocycling and UDMA release; abbreviations of groups are: $1: 24 \mathrm{~h}, 2: 48 \mathrm{~h}, 3: 72 \mathrm{~h}, 4: 1 \mathrm{wk}, 5: 4 \mathrm{wk}, 6: 12 \mathrm{wk}, 7: 1000$ cycles, 8: 2000 cycles, 9: 3000 cycles.

The highest amount of UDMA was released at 1wk from the samples immersed in the ethanol. The release of UDMA from the samples immersed in water was decreased over the time. However, the release of UDMA from the samples immersed in acid citric was increased over the time. There were not any significant differences between the amounts of released UDMA from the samples immersed in acid citric at different time points.

There was a direct relation between an increase in the number of cycles of thermocycling and the amount of leached monomers from the samples immersed in citric acid and ethanol, but such relation was not found in those immersed in water and lactic acid (Fig. 3).

\subsection{TEGDMA}

The samples immersed in water released the lowest amount of TEGDMA while those immersed in ethanol released the highest amount of this monomer. At 48 and $72 \mathrm{~h}$, the lowest amount of leached TEGDMA was released in water and the highest amount was released in ethanol. At 1 wk, the samples immersed in water significantly released less TEGDMA than those immersed in the other media, but the difference between the those of the other media was not significant. At $4 \mathrm{wk}$, the lowest amount of TEGDMA was released in water, and the highest amount was detected in citric acid. At $12 \mathrm{wk}$, samples immersed in ethanol significantly released more TEGDMA than those of the other groups.

There were not any significant differences in the amount of released TEGDMA between 24, 48, and $72 \mathrm{~h}$, but TEGDMA was significantly release more at 4 wk. Generally, the elution of TEGDMA from composite samples was increased over the time (Fig. 4).

After 1000 cycles of thermocycling, the highest amount of TEGDMA was observed in ethanol and the lowest amount 


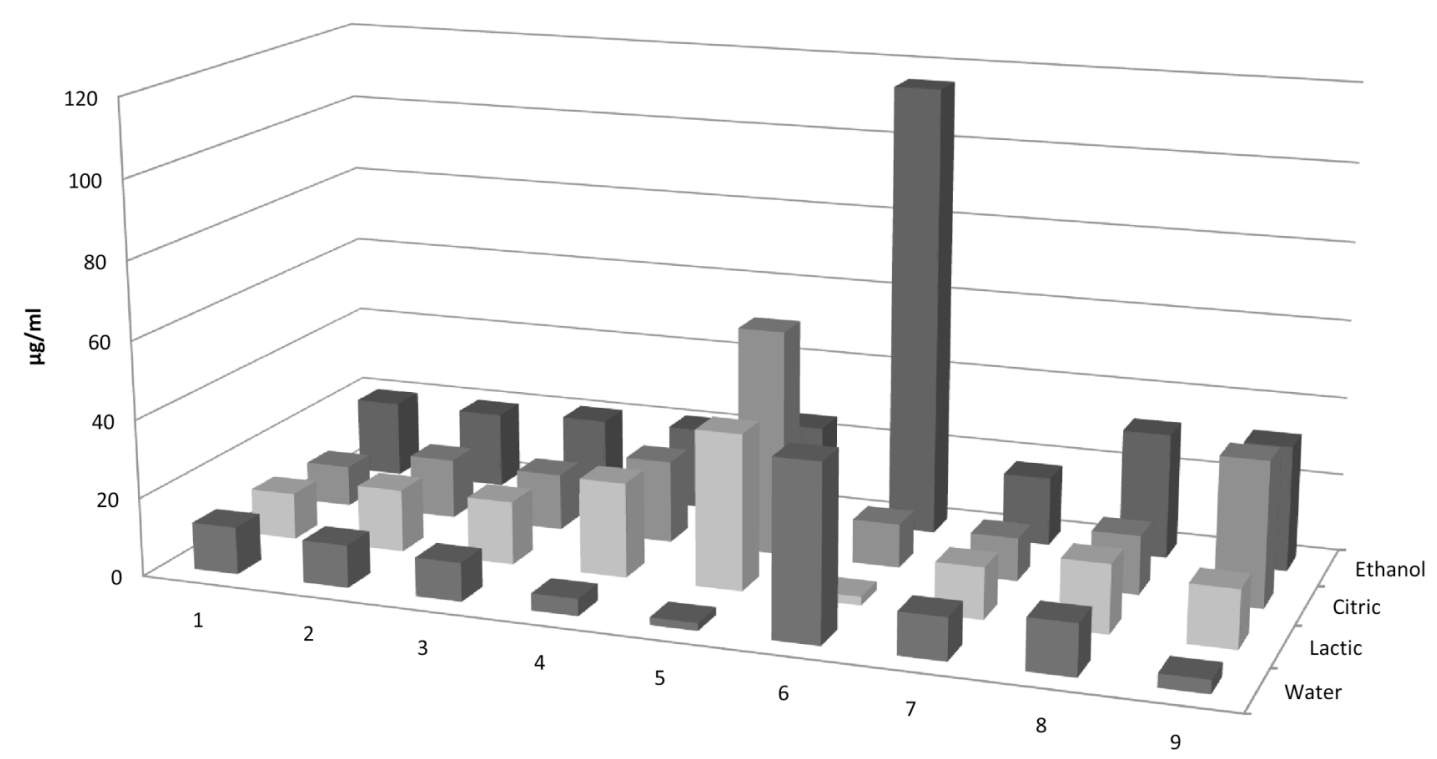

Fig. (4). The relationship between immersion medias and different immersion times and thermocycling and TEGDMA release; abbreviations of groups are: 1: $24 \mathrm{~h}, 2: 48 \mathrm{~h}, 3: 72 \mathrm{~h}, 4: 1 \mathrm{wk}, 5: 4 \mathrm{wk}, 6: 12 \mathrm{wk}, 7: 1000$ cycles, 8: 2000 cycles, 9: 3000 cycles

of it was detected in water. There were not any significant differences between the groups after 2000 thermal cycles. After 3000 cycles, the higher amounts of TEGDMA were released from the samples immersed in ethanol and acid citric compared to the other two solvents.

\subsection{Bis-EMA}

Bis-EMA was only detected in ethanol solution, and it was not detected in water, acid lactic, and acid citric by HPLC. The amount of released Bis-EMA in ethanol was higher compared to the other monomers.

The release of Bis-EMA from the samples immersed in ethanol was increased over the time, and highest amount of released Bis-EMA was found at $12 \mathrm{wk}$. In addition, a higher amount of Bis-EMA was released from the samples which underwent a higher number of thermal cycles. (Table 2).

\section{DISCUSSION}

Leaching components from dental composites could impair mechanical properties of the restoration, and also it has raised some concerns about the biocompatibility of dental composites [6, 17]. Leaching of monomers is affected by several factors including chemical structure of resin (type of fillers, monomer/filler proportion, type of monomer, etc) [18], light-curing units [19], and environmental conditions (such as presence of saliva, foods, and beverages) [20]. In the present study, the hypothesis was that the food stimulated liquids (organic acids and ethanol) and thermal shocks can affect the release of monomers from resin composite restorations. The present results revealed that $75 \%$ aqueous ethanol solution significantly released more monomers than the other solvents. The difference between lactic acid and citric acid was not significant, but these solvents were more effective in releasing monomers than distilled water.

There is a very limited number of studies evaluating the effects of organic acids on the leaching of monomers [20], but there are several reports regarding the effects of organic acids on the mechanical and surface characteristics of com- posite resins $[5,21]$. Asmussen has reported that the hardness of resin composite significantly decreased after $1 \mathrm{~d}$ of immersing in ethanol, acetic acid, propionic acid, and lactic acid [8]. Chadwick and colleagues exposed composite samples to lactate and acetate buffers and reported that lactate decreased the hardness of resin composite but citrate had no effect on it [22]. Those findings could imply that organic acids have a softening effect on the polymeric structure of dental composite restorations. It has been shown that irreversible degradation of resin composites due to leaching of components occurs in the presence of ethanol [23]. In addition, Lee and colleagues evaluated the release of monomers from three resin composites immersed in ethanol and two organic acids of dental plaque, and they found that ethanol and organic acids increased leaching of monomers from the resin composites [20]. In the present study, it was found that aqueous ethanol solution, lactic acid, and citric acids enhance the leaching of monomers. An important factor that affects the release pattern of monomers is solubility parameters of the solvents. Weathering agents, such as ethanol, can simulate clinically expected effects of food and saliva and accelerate the degradation of resin composites $[12,13]$.

The composite resin which was used in the present study is a relatively new nano-hybrid dental composite (Supreme Filtek) that contains the following monomers: Bis-GMA, UDMA, TEG-DMA and Bis-EMA. In the present study, all these monomers were detected by HPLC. The present results showed that amount of eluted Bis-GMA was lower than the other monomers (Bis-GMA $<$ UDMA $<$ TEGDMA and BisEMA). The manufacturer's catalogue does not represent the percentage of each monomer; however, due to the presence of UDMA in this resin composite, it could be assumed that the initial amount of Bis-GMA and subsequent TEGDMA, as a diluent monomer for Bis-GMA, has decreased in this composite. In addition, an important factor that affects the leaching of monomers is the size of their molecules. Smaller molecules are expected to leach more rapidly than larger and bulkier molecules [24]. In the present study, TEGDMA was released more than Bis-GMA and UDMA which is explain- 
able by the size and weight of monomers [25]. The results of the present study is in accordance with those of studies of ortengrenu (2001), Lee (1998), Tabatabae (2008), and spahl (1998) that revealed the TEGDMA monomer leached more than other monomers [1, 19, 20, 24].

It should be noticed that the overall concentrations of leached monomers increased as a function of time up to the maximum storage period of three months suggesting further leaching may be occur over the time.

\section{CONCLUSIONS}

It could be concluded that food and drink stimulated liquids which used in the present study increased the amount of some of the monomers released from the composite resin. Thermal shocks and storage time are other factors that increased the release of monomers from the composite resin.

\section{CONFLICT OF INTEREST}

The authors certify that they have no commercial or associative interest that represents a conflict of interest in connection with the manuscript.

\section{ACKNOWLEDGEMENTS}

The authors sincerely thank Dr.Kharrazi for the statistical analysis.

\section{REFERENCES}

[1] Spahl W, Budzikiewicz H, Geurtsen W. Determination of leachable components from four commercial dental composites by gas and liquid chromatography/mass spectrometry. J Dent 1998; 26: 13745.

[2] Ferracane JL. Current trends in dental composites. Crit Rev Oral Biol Med 1995; 6: 302-18.

[3] Ferracane JL. Elution of leachable components from composites. J Oral Rehabil 1994; 21: 441- 52

[4] Porto IC, Soares LE, Martin AA, Cavalli V, Liporoni PC. Influence of the photoinitiator system and light photoactivation units on the degree of conversion of dental composites. Braz Oral Res 2010; 24: 475-81.

[5] Rode KM, Kawano Y, Turbino ML. Evaluation of curing Light distance on resin composite microhardness and polymerization. Oper Dent 2007; 32: 571-8.

[6] Geurtsen W. Lehmann F, Spahl W, Leyhausen G. Cytotoxicity of 35 dental resin composite monomers/additives in permanent 3T3 and three human primary fibroblast cultures. J Biomed Mater Res 1998; 41: 474-80.

[7] Rodrigues Filho LE, Burger LA, Kenshima S, Bauer JR, Medeiros IS, Muench A. Effect of light-activation methods and water storage on the flexural strength of two composite resins and a compomer. Braz Oral Res 2006; 20: 143-7.

[8] Asmussen E. softening of BisGMA-based polymers by ethanol and by organic acids of plaque. Scand J Dent Res 1984; 92: 257-61.

[9] Lee SY, Greener EH, Mueller HJ, Chiu CH. Effect of food and oral simulating fluids on dentine bond and composite strength. J Dent 1994; 22: 325-9.

[10] Yap AU, Wattanapayungkul P, Chung SM. Influence of the polymerization process on composite Resistance to chemical degradation by food-simulating liquids. Oper Dent 2003; 28: 723-7.

[11] Akova T, Ozkomur A, Aytutuldu N, Toroglu MS. The effect of food simulants on porcelain-composite bonding. Dent Mater 2007; 23: 1369-72.

[12] McKinney JE, Wu W. Chemical softening and wear of dental composites. J Dent Res 1985; 64: 1326-31.

[13] $\mathrm{Wu} \mathrm{W}$, McKinney JE. Influence of chemicals on wear of dental composites. J Dent Res 1982; 61: 1180-3.

[14] Tarle Z, Meniga A, Knezević A, Sutalo J, Ristić M, Pichler G. Composite conversion and temperature rise using a conventional, plasma arc, and an experimental blue LED curing unit. J Oral Rehabil 2002; 29: 662-7.

[15] Uhl A, Mills RW, Janet KD. Photoinitiator dependent composite depth of cure and Knoop hardness with halogen and LED light curing units. Biomaterial $2003 ; 24: 1787-95$.

[16] Ferracane JL, Condon JR. Rate of elution leachable components from composite. Dent Mater 1990; 6: 282-7.

[17] Brandt WC, Schneider LF, Frollini E, Correr-Sobrinho L, Sinhoreti MA. Effect of different photo-initiators and light curing units on degree of conversion of composites. Braz Oral Res 2010; 24: 26370 .

[18] Shajii L, Santerre JP. Effect of filler content on the profile of released biodegradation products in micro-filled BisGMA/TEGDMA dental composite resins. Biomaterials 1999; 20: 1897-908.

[19] Tabatabaee MH, Mahdavi H, Zandi S, Kharrazi MJ. HPLC analysis of eluted monomers from two composite resins cured with LED and halogen curing lights. J Biomed Mater Res B Appl Biomater 2009; 88: 191-6.

[20] Lee SY, Huang HM, Lin CY, Shih YH. Leached components from dental composites in oral simulating fluids and the resultant composite strengths. J Oral Rehabil 1998; 25: 575-88.

[21] O'Donnell JN, Longhorst SE, Fow MD, Antonucci JM, Skrtic D. Light-cured dimethacrylate-based resins and their composites: comparative study of mechanical strength, water sorption and ion release. J Bioact Compat Polym 2008; 23: 207-26.

[22] Chadwick RG, McCabe JF, Walls AW, Storer R. The effect of storage media upon the surface microhardness and abrasion resistance of three composites. Dent Mater 1990; 6: 123-8.

[23] Lee SY, Greener EH, Menis DL. Detection of leached moieties from dental composites in fluids simulating food and saliva. Dent Mater 1995; 11: 348-53.

[24] Ortengren U, Wellendorf H, Karlsson S, Ruyter IE. Water sorption and solubility of dental composites and identification of monomers released in an aqueous environment. J Oral Rehabil 2001; 28: 1106-15.

[25] Sideridou I, Tserki V, Papanastasiou G. Study of water sorption, solubility and modulus of elasticity of light-cured dimethacrylatebased dental resins. Biomaterials 2003; 24: 655-65.

Received: February 18, 2013

(C) Tabatabaei et al.; Licensee Bentham Open.

This is an open access article licensed under the terms of the Creative Commons Attribution Non-Commercial License (http://creativecommons.org/licenses/by-nc/3.0/) which permits unrestricted, non-commercial use, distribution and reproduction in any medium, provided the work is properly cited. 